\title{
Treatment of an atypical metastatic meningioma: a case report
}

\author{
Conca $\mathrm{R}^{1, *}$, Roviello $\mathrm{G}^{1}$, Cerase $\mathrm{A}^{2}$, Mazzei $\mathrm{MA}^{4}$, Miracco $\mathrm{C}^{3}$, Mastrogiulio $\mathrm{MG}^{3}$, Marsili $\mathrm{S}^{1}$ and Francini $\mathrm{G}^{1, *}$ \\ ${ }^{1}$ Medical Oncology, University of Siena, Policlinico Le Scotte, Viale Bracci 11, 53100 Siena, Italy \\ ${ }^{2}$ Unit NINT Neuroimaging and Neurointervention, Department of Neurological and Sensorial Sciences, University of Siena, Italy \\ ${ }^{3}$ Department of Human Pathology and Oncology, Section of Pathological Anatomy, University of Siena, Italy \\ ${ }^{4}$ Department of Human Pathology and Oncology, Section of Radiological Sciences, University of Siena, Italy
}

\begin{abstract}
Meningiomas are common intracranial tumors which usually pursue a benign course. Extracranial metastases from meningiomas are very rare and the lung is the most common site. We report a 27 year old girl with an intracranial atypical meningioma with pulmonary metastasis which had been misdiagnosed as lung sequestration upon chest CT examination. She underwent subtotal surgical resection of the meningioma in 2006 and surgical removal of the lung metastasis in 2009. Then, the patient developed pleural, lung, periesophageal and diaphragmatic nodal metastases, despite only subtle increase of the intracranial residual meningioma. Therefore, she was treated by Doxil (pegylated liposomal doxorubicin) and bevacizumab with a progression of disease after three cycles and then with hydroxyurea for two months with a dimensional increase of metastatic lesions. After adding sorafenib to hydroxyurea the patient showed a further progression disease and finally died for respiratory insufficiency. Metastatic meningiomas have been rarely reported. Hydroxyurea is one of the most used drug in recurrent and metastatic meningiomas, despite modest results are obtained. Further chemotherapy strategies or biological agent must be investigated in clinical trials.
\end{abstract}

Keywords: metastatic meningioma; chemotherapeutic agents; doxorubicin; bevacizumab; hydroxyurea

\section{Introduction}

Intracranial meningiomas behave benign (WHO grade I) in about $90 \%$ of the cases, with slow growth, and without recurrences after surgical removal. Atypical (WHO grade II) and anaplastic (WHO grade III) meningiomas are more aggressive, and show a high risk of local recurrences, as well as, more rarely, of extra cranial dissemination [1, $2,3]$. Metastatic meningiomas are usually resistant to chemotherapy and target therapy. The purpose of this case report is to increase the knowledge about the diagnosis and treatment of metastatic meningiomas.

\section{Case report}

In November 2006, an otherwise healthy 27-year-old girl presented with headache, vague balance difficulties, right hemisensory and hemiparetic deficits. Head computed tomography (CT), magnetic resonance imaging (MRI), and MR angiography (MRA) (Figure 1) showed a large left frontal and parietal extra-axial mass, infiltrating the superior sagittal sinus, consistent with meningioma. Preoperative chest radiographs revealed a left posterior basal opacity. Upon chest CT, this lesion was $65 \mathrm{~mm}$ in maximum diameter, showed a wide pleural contact, smooth and sharp borders, and sporadic calcifications on the pleural surface (Figure 2). A diagnosis of pulmonary intralobar sequestration was made because of the identification of the venous drainage into the left inferior pulmonary vein, but underestimating the lack of the identification of an arterial supply. The patient underwent

*Corresponding authors: Conca R and Francini G, Medical Oncology, University of Siena, Policlinico Le Scotte, Viale Bracci 11, 53100 Siena, Italy, Fax: +39 0577586429 ; E-mail: raffaeleconca@hotmail.it; giandomenicoroviello@hotmail.it

Received 17 November 2012 Revised 5 March 2013 Accepted 12 March 2013 Published 19 March 2013

Citation: Conca R, Roviello G, Cerase A, Mazzei MA, Miracco C, Mastrogiulio MG, Marsili S, Francini G (2013) Treatment of an atypical metastatic meningioma: a case report. J Cancer Res Ther 1: 99-104. doi:10.14312/2052-4994.2013-15

Copyright: (C) 2013 Conca R, et al. This is an open-access article distributed under the terms of the Creative Commons Attribution License, which permits unrestricted use, distribution and reproduction in any medium, provided the original author and source are credited. 
a subtotal resection of the intracranial mass through a left frontoparietal approach. Pathologic evaluation showed a meningioma with high to moderate cellularity, pattern less areas, atypical nuclear features, with prominence

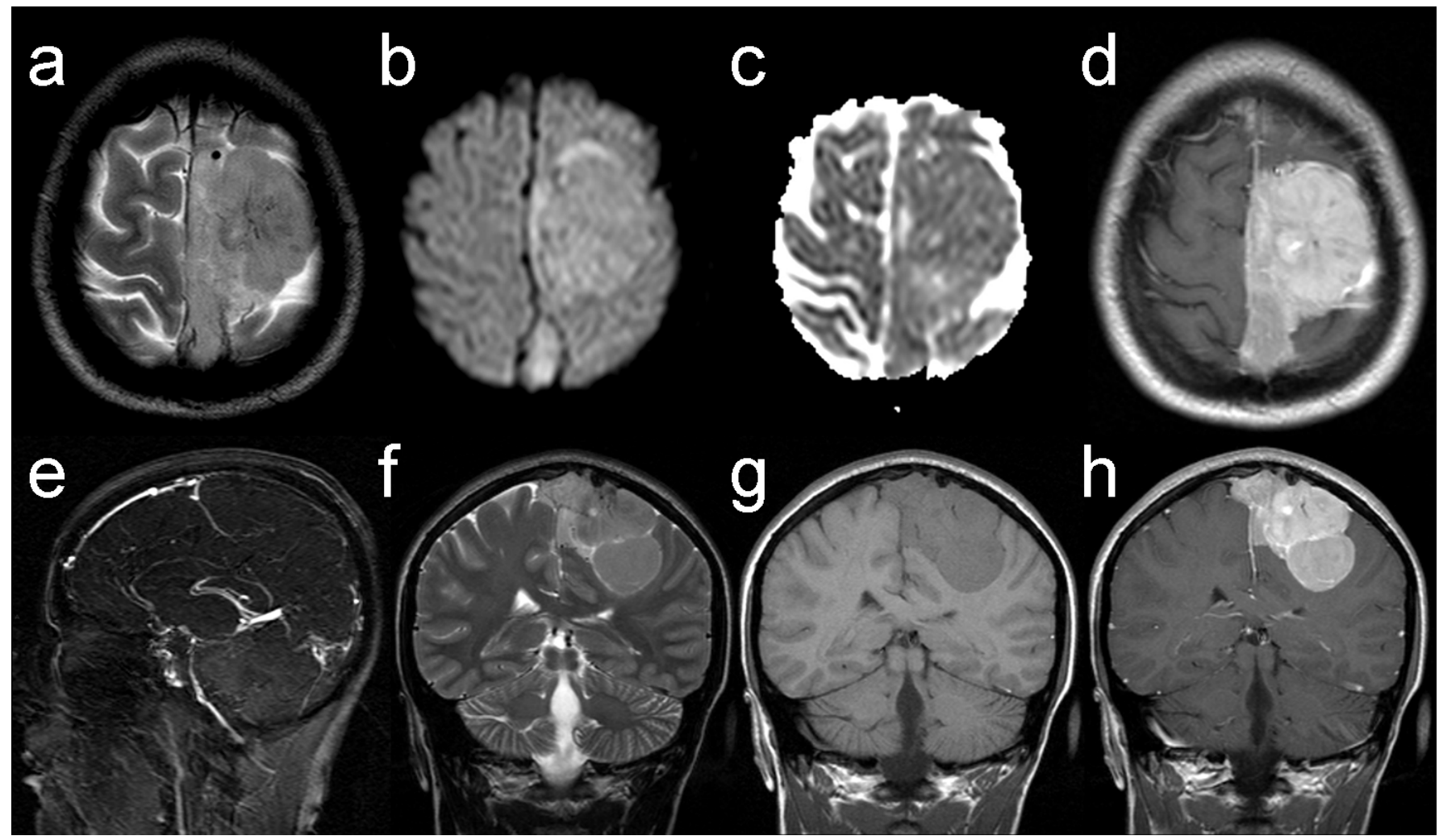

Figure 1 Magnetic resonance (MR) imaging and angiography of the head. (a) Unenhanced T2-weighted; (b) diffusion-weighted; (c) apparent diffusion coefficient; (d) gadolinium-enhanced T1-weighted, axial MR images; (e) 2D phase contrast sagittal MR angiogram; (f) unenhanced T2-weighted and T1weighted; (h) gadolinium-enhanced T1-weighted, coronal MR images clearly shows the infiltration of the middle and posterior portion of the superior sagittal sinus. The lesion shows some degree of inhomogeneous signal intensity, and homogeneous gadolinium-enhancement

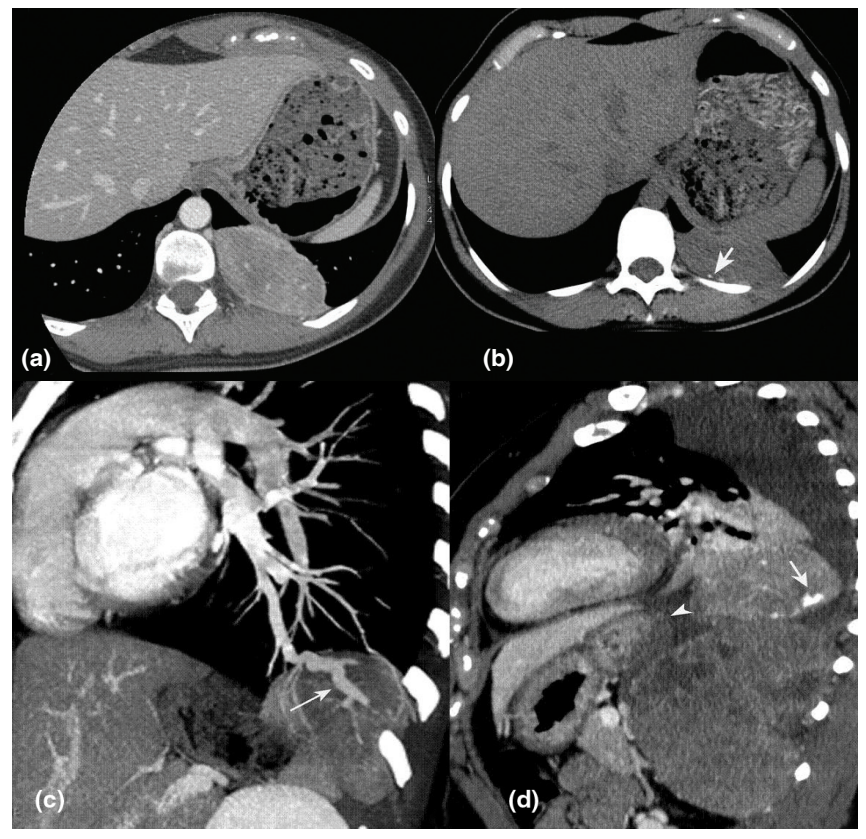

Figure 2 (a) axial CT image after iv contrast material administration showed an ipervascular mass with wide pleural contact; (b) presenting focal calcifications on the pleural surface on the unenhanced CT scan (arrow); (c) Sagittal-oblique reformatted, demonstrated the venous drainage of the mass into the left inferior pulmonary vein (white arrow), suggesting the possible diagnosis of intralobar pulmonary sequestration; (d) A sagittal reformat of the CT examination performed three years later, showed a significant increase in size of the lesion with calcifications (white arrow) and the appearance of a new lesion, located beneath the first, displacing the diaphragm (arrow head) of nucleoli, and rare mitotic figures (less than $1 / 1 \mathrm{~mm}^{2}$ ). Tumor cell proliferation index, such as evaluated by anti-ki-67 MIB1 antibody (rabbit monoclonal antibody, diluted 1: 100; NeoMarkers, Inc, Fremont, CA, USA), was about 7\%; tumor cells positive to progestinic receptors, and EGFR were $50 \%$, and $70 \%$, respectively, p53 was negative.

A diagnosis of grade II meningioma, according to WHO 2007 grading system, was rendered (Figure 3). Considering the very young age of patient, the absence of symptoms and the unfavourable risk/benefit ratio, the external beam radiotherapy (EBRT) of the residual lesion wasn't performed. The intracranial mass remained stable for three years. In December 2009, brain MRI and MRA showed a subtle degree of growth of the residual disease. In the same period, the patient referred abdominal pain associated to short breathing. A chest CT showed a dramatic increase in volume of the left lung lower lobe lesion (maximum diameter $72 \mathrm{~mm}$ ), showing calcifications and necrotic areas, associated with ipsilateral pleural effusion with total atelectasis of the ipsilateral lower lobe lung.

Another lesion (maximum diameter $125 \mathrm{~mm}$ ) with similar features was evident caudally, between the lesion and the dorsal vertebral column, in the left costophrenic sinus, apparently arising in the parietal 
pleura, shifting the diaphragm forward and down (Figure 2). A transthoracic biopsy was performed, and histology demonstrated meningioma metastasis. In January 2010, both the pleuropulmonary masses were surgically removed (Figure 2). When compared to the primary lesion, metastatic deposits showed huge areas with a higher degree of malignancy, showing severe nuclear atypia, a higher number of mitoses $\left(12 / 1 \mathrm{~mm}^{2}\right.$ vs $1 / 1$

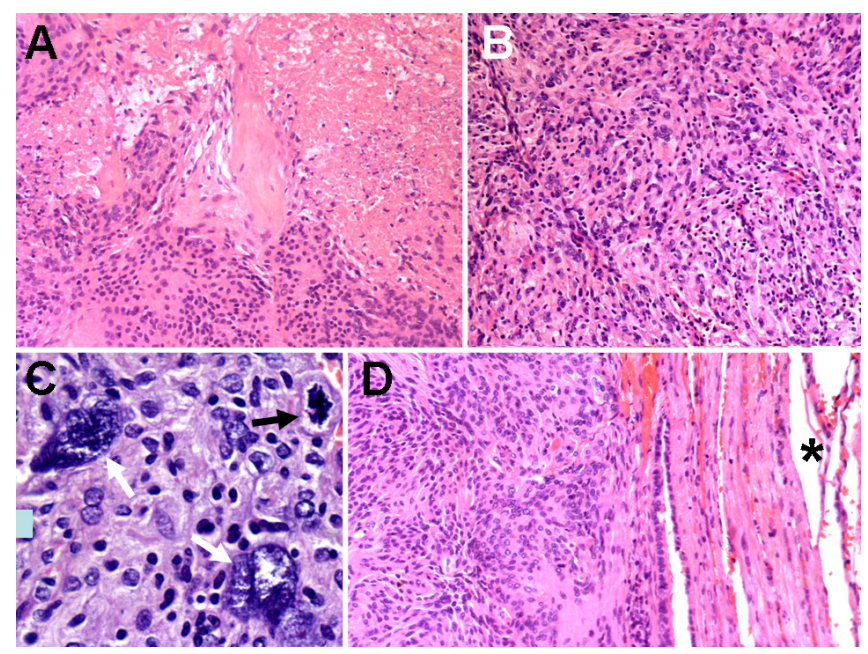

Figure 3 (a) Necrosis; (b) as well as patternless areas with nuclear atypia, scattered, anaplastic nuclei; (c) white arrows and mitoses (black arrow) were observable in primary meningioma; (d) A metastatic meningioma deposit to the lung (the asterisk indicates lung alveoli)

$\mathrm{mm}^{2}$ ), a higher proliferation index (Ki-67 labeling index: about $20 \%$ vs $7 \%$ ). Additionally an immunohistochemical staining demonstrated a lack of expression of c-Erb-B2, CD117 (c-kit) and estrogen receptors, while EGFR was expressed. Chest CT images obtained at diagnosis were revised, and the possibility of lung metastases already at the diagnosis was considered. The issue of the radiological and CT differential diagnosis of the thoracic mass is beyond the scope of this paper, and will be addressed elsewhere. The patient began a close follow-up until September 2010 when a chest and abdomen CT revealed the presence of multiple pleural lesions in left hemithorax (maximum diameter, $38 \mathrm{~mm}$ ) and a large lesion near diaphragmatic hiatus and left diaphragmatic pilar with some pathological diaphragmatic thickenings in left costal-phrenic margin (maximum diameter, $36 \mathrm{~mm}$ ). A millimetric parenchymal lung lesion of the left lower lobe was evident too. Excluding any local treatment for the systemic dissemination of the tumour, in August 2010, she began treatment with Doxil (pegylated liposomal doxorubicin) $50 \mathrm{mg} / \mathrm{m}^{2}$ and bevacizumab $75 \mathrm{mg} / \mathrm{m}^{2}$ every 21 days [4, 5]. After three cycles of this regimen, a total body CT showed a dimensional increase of pleural and periesophageal lesion (maximum diameter of the last one, $75 \mathrm{~mm}$ ), with some border line para-aortic lymph nodes. From October 2010 treatment with hydroxyurea $20 \mathrm{mg} / \mathrm{m}^{2} /$ die was undertaken. In December 2010, after two months of this treatment a total body CT showed a volumetric growth of pleural lesions with a major central necrotic component. Therefore, considering the over expression of EGFR in meningioma and its involvement in the proliferation and/or differentiation of meningothelial cells $[6,7]$, a treatment with sorafenib (EGFR inhibitor) 400 $\mathrm{mg} /$ die and hydroxyurea $20 \mathrm{mg} / \mathrm{m}^{2} /$ die was undertaken $[8,9]$. The patient performed this treatment for 4 months with no severe toxicity. Then, a total body CT after 4 months of the tyrosine kinase inhibitor and hydroxyurea showed a new further dimensional increase of pleural and meningeal lesions, a modest increase of para-aortic lymph nodes with appearance of ascites. Considering the severe clinical conditions of the patient, we opted for best supportive care. After 2 months the patient died for respiratory insufficiency.

\section{Discussion}

Meningiomas represent approximately $13-26 \%$ of all intracranial tumours [10]. The most common locations are along the sagittal sinus, and over the cerebral convexity such as in the case reported herein [11]. The WHO grade I meningiomas have usually a benign behaviour. The atypical (WHO grade II) and anaplastic (WHO grade III) meningiomas are more aggressive, with a greater proliferative capacity [12]. The local recurrence rates of meningiomas, even after complete resection varies from 9 to $32 \%$ [13]. Metastatic spread outside the skull is rare, and correlates with the histological grade. Exceptionally reported in grade I, it raises to $5 \%$ in grade II, and to $30 \%$ in grade III [14].

Meningioma preferentially disseminate through the cerebrospinal or lymphatic route $[15,16]$. Metastatic spread to the lung and pleura (the most frequent sites) $[17,18]$, and to other extracranial organs is thought to occur through the blood route, following invasion of dural venous sinuses, as probably occurred in our case, and cranial veins $[3,12,19]$. Some authors have also considered surgery as a risk factor for extracranial spreading [20].

Radical surgery is the treatment choice, after taking into account its usually slow growth, lack of aggressiveness, and the benefit-risk ratio for the patient [21]. A radical resection is not always possible, in particular for tumours in tight contact with vital structures or with high infiltration of venous sinus and cranial base such as in the patient reported herein.

Radiotherapy is usually not performed in grade I meningiomas, being recommended only after partial resection, to prevent local recurrences, or in unresectable forms $[22,23,24]$ also considering the variety of adverse effects, including radiation necrosis, which may occur after SNC irradiation [25, 26]. Postoperative radiotherapy was found to improve the progression free survival in grade II [27] (poorly defined) and III meningiomas [28, $29,30]$. Stereotactic radiation, with a high-dose radiation to a target volume, is an alternative way to reduce adverse effects of radiotherapy. Radiotherapy was not performed in our case, considering the very young age of patient, with 
an unfavourable risk/benefit ratio [31]. Furthermore, indication for radiation therapy in meningiomas involving large vessels is still debated, since there are not long term follow up [32].

Chemotherapy is usually applied to inoperable lesions, especially in the setting of tumor progression or recurrence, with modest results. Among the traditional cytotoxic drugs, hydroxyurea is the most experienced. It is an oral antimetabolite commonly used in the treatment of haematologic malignancies whose mechanism of action is to inhibit ribonucleotide reductase and causes apoptosis in phase S of the cell cycle [33]. Preliminary results of clinical studies suggest that hydroxyurea has modest activity against recurrent and inoperable meningiomas, and can induce long term stabilization in some patients, with an acceptable safety [34, 35, 36, 37].

Doxil is a formulation of pegylated liposomal doxorubicin with a prolonged circulation time and selective accumulation in ipervascularized tissue as solid tumors. It appears to have citostatic and radiosensitizing effect in brain tumor [38, 39]. Travitzky et al. reported a single case of a 60 year old woman with massive pleuropulmonary metastases from recurrent cranial meningioma treated with Doxil ( $50-37.5 \mathrm{mg} / \mathrm{m}^{2}$ ) for 18 months with regression of pleuropulmonary metastases and disappearance of pleural fluid [4]. In the patient reported herein, treatment with those chemotherapeutic agents has provided no benefit.

Somatostatin is a neuropeptide produced in hypothalamus that regulates the endocrine end exocrine secretions as well as the gastrointestinal mobility. Somatostatin and its synthetic analogs, binding their receptors, can have e antitumor effect by stimulation of apoptosis, inhibition of angiogenesis and suppression of tumor-stimulating growth factors [40]. Somatostatin receptors, in particular sst2A subtype, are overexpressed in most menigiomas and their inhibition can suppress the meningioma cell growth [41]. A prospective pilot trial of sustained-release somatostatin (Sandostatin LAR) in 16 patients with recurrent meningiomas was conducted obtaining a partial response in thirty one percent of patients with acceptable toxicity $[42,43]$. A recent phase II trial testing a new somatostatin analogue with a wide receptor spectrum has recently opened [44].

Recent publications report an intense search for new molecular markers that may serve as potential therapeutic target. VEGF (vascular endothelial growth factor) is an important regulator of angiogenesis and has been implicated in pathologic angiogenesis associated with tumor growth [45]. Meningiomas are extremely vascular tumor and VEGF may have a critical role in this characteristic $[46,47]$. Bevacizumab is humanized monoclonal antibody that inhibits VEGF and it has been the first antiangiogenic therapy to be approved in solid tumor. Many trials have showed its efficacy and good safety as single agent or with chemotherapy for patients with recurrent glioblastoma. Additionally, it can induce radiation sensitivity in solid cancers inhibiting the angiogenesis [48]. In the literature there are few case report on the treatment of meningiomas with Bevacizumab but the treatment of recurrent or metastatic meningioma with VEGF inhibitor with other chemotherapeutic agents may be very effective. EGFR (epidermal growth factor receptor) is a member of the receptor tyrosine kinase HER family that is crucial for the regulation of cell division and tumor growth. It's over expression is associated with a poor prognosis in various epithelial tumor. In 1987 Weisman et al, demonstrated that EGFR is involved in the proliferation and differentiation of meningothelial cells [6].

In 2010, Wernicke et al. reported an inverse correlation between EGFR expression and tumor grade in human meningioma [7]. EGFR activation increase resistance to apoptosis, promotes angiogenesis and impairs immune surveillance. A recent small phase II trial has examined the efficacy of gefitinib and erlotinib, EGFR inhibitors, in 25 patients with recurrent meningiomas [9]. The treatment was well tolerated, but the two molecules did not show significant benefit. Although other EGFR inhibitors exist, very few trials have examined their therapeutic potential for treating meningiomas. Therefore, we opted for a multi-target and EGFR inhibitor as sorafenib that may decrease the growth-stimulatory mechanism in this kind of tumor. However, in the patient reported herein neither bevacizumab nor sorafenib showed significant activity.

An attractive alternative therapeutic approach is the inhibition of platelet derived growth factor receptor (PDGF) pathway. Because of the high expression of PDGF ligand $\mathrm{AA}$ and $\mathrm{BB}$ and the PDGF beta receptor in human meningioma cells [49-54]. Imatinib mesylate (inhibitor of PDGF receptor alfa e beta, c-Kit tyrosine kinases and $\mathrm{Bcl}-\mathrm{Abl}$ ) has been investigated as a possible therapeutic option for recurrent meningiomas in some phase II trials with modest results [55-57]

\section{Conclusions}

Histological features of atypia or malignancy, as well as large vessel invasion may be associated with an unfavourable course in meningioma, and the occurrence of extra-cranial spread, although infrequent, must always be considered. Currently, the traditional chemotherapeutic agents have provided minimal benefit in meningiomas recurring after surgery. In spite of the negative results of the alternative treatments reported in this case, we believe that new strategies are required in metastatic meningioma.

There are very few open trials testing target therapies in this pathology probably because the molecular pathways driving meningioma progression are still mostly unknown. Only a better elucidation of these pathways can help us to modify treatment paradigms in this uncommon tumor. 


\section{Conflict of interest}

The authors wish to express that they have no conflict of interest.

\section{References}

[1] Figueroa BE, Quint DJ, McKeever PE, Chandler WF (1999) Extracranial metastatic meningioma. Br J Radiol 72:513-516.

[2] Fulkerson DH, Horner TG, Hattab EM (2008) Histologically benign intraventricular meningioma with concurrent pulmonary metastasis: case report and review of the literature. Clin Neurol Neurosurg. 110:416-419.

[3] Lee GC, Choi SW, Kim SH, Kwon HJ (2009) Multiple extracranial metastases of atypical meningiomas. J Korean Neurosurg Soc 45:107-111.

[4] Travitzky M, Libson E, Nemirovsky I, Hadas I, Gabizon A (2003) Doxil-induced regression of pleuro-pulmonary metastases in a patient with malignant meningioma. Anticancer Drugs 14:247250.

[5] Puchner MJ, Hans VH, Harati A, Lohmann F, Glas M, et al. (2010) Bevacizumab-induced regression of anaplastic meningioma. Ann Oncol 21:2445-2446.

[6] Wernicke AG, Dicker AP, Whiton M, Ivanidze J, Hyslop T, et al. (2010) Assessment of Epidermal Growth Factor Receptor (EGFR) expression in human meningioma. Radiat Oncol 30:5:46.

[7] Weisman AS, Villemure JG, Kelly PA (1986) Regulation of DNA synthesis and growth of cells derived from primary human meningiomas. Cancer Res 46:2545-2550.

[8] Hahn BM, Schrell UM, Sauer R, Fahlbusch R, Ganslandt O, et al. (2005) Prolonged oral hydroxyurea and concurrent 3d-conformal radiation in patients with progressive or recurrent meningioma: results of a pilot study. J Neurooncol 74:157-165.

[9] Norden AD, Raizer JJ, Abrey LE, Lamborn KR, Lassman AB, et al. (2010) Phase II trials of erlotinib or gefitinib in patients with recurrent meningioma. J Neurooncol 96:211-217.

[10] Alexiou GA, Gogou P, Markoula S, Kyritsis AP (2010) Management of meningiomas. Clin Neurol Neurosurg 112:177-1782.

[11] Mahmood A, Caccamo DV, Tomecek FJ, Malik GM (1993) Atypical and malignant meningiomas: a clinicopathological review. Neurosurgery 33:955-963.

[12] Garcia-Conde M, Roldan-Delgado H, Martel-Barth-Hansen D, Manzano-Sanz C (2009) Anaplastic transformation of an atypical intraventricular meningioma with metastases to the liver: case report. Neurocirugia (Astur) 20:541-549.

[13] Mori H, Sugiyama Y, Terabayashi T, Niida H, Yamamoto K, et al. (1988) Recurrent meningioma with malignant changes and extracranial multiple metastases. No Shinkei Geka 16:899-902.

[14] Enam SA, Abdulrauf S, Mehta B, Malik GM, Mahmood A (1996) Metastasis in meningioma. Acta Neurochir (Wien) 138:11721177.

[15] Chamberlain MC, Glantz MJ (2005) Cerebrospinal fluid-disseminated meningioma. Cancer 103:1427-1430.

[16] Shintaku M, Hashimoto K, Okamoto S (2007) Intraventricular meningioma with anaplastic transformation and metastasis via the cerebrospinal fluid. Neuropathology 27:448-452.

[17] Karasick JL, Mullan SF (1974) A survey of metastatic meningiomas. J Neurosurg 40:206-212.

[18] Tao LC (1991) Pulmonary metastases from intracranial meningioma diagnosed by aspiration biopsy cytology. Acta Cytol 35:524-528.

[19] Abboud M, Haddad G, Kattar M, Aburiziq I, Geara FB (2009) Extraneural metastases from cranial meningioma: a case report. Radiat Oncol 6:4:20.

[20] Rawat B, Franchetto AA, Elavathil J (1995) Extracranial metastases of meningioma. Neuroradiology 37:38-41.

[21] Yano S, Kuratsu J, Kumamoto Brain Tumor Research Group (2006) Indications for surgery in patients with asymptomatic meningiomas based on an extensive experience. J Neurosurg 105:538-543.

[22] Barbaro NM, Gutin PH, Wilson CB, Sheline GE, Boldrey EB, et al. (1987) Radiation therapy in the treatment of partially resected meningiomas. Neurosurgery 20:525-528.
[23] Goldsmith BJ, Wara WM, Wilson CB, Larson DA (1994) Postoperative irradiation for subtotally resected meningiomas. A retrospective analysis of 140 patients treated from 1967 to 1990. J Neurosurg 80:195-201.

[24] Tanzler E, Morris CG, Kirwan JM, Amdur RJ, Mendenhall WM (2010) Outcomes of WHO Grade I meningiomas receiving definitive or postoperative radiotherapy. Int J Radiat Oncol Biol Phys 79:508513.

[25] Cohen ME, Duffner PK (1991) Long-term consequences of CNS treatment for childhood cancer, Part I: Pathologic consequences and potential for oncogenesis. Pediatr Neurol 7:157-163.

[26] Duffner PK, Cohen ME (1991) The long-term effects of central nervous system therapy on children with brain tumors. Neurol Clin 9:479-495.

[27] Aghi MK, Carter BS, Cosgrove GR, Ojemann RG, Amin-Hanjani S, et al. (2009) Long-term recurrence rates of atypical meningiomas after gross total resection with or without postoperative adjuvant radiation. Neurosurgery 64:56-60

[28] Debus J, Wuendrich M, Pirzkall A, Hoess A, Schlegel W, et al. (2001) High efficacy of fractionated stereotactic radiotherapy of large base-of-skull meningiomas: long-term results. J Clin Oncol 19:3547-3553.

[29] Hug EB, Devries A, Thornton AF, Munzenride JE, Pardo FS, et al. (2000) Management of atypical and malignant meningiomas: role of high-dose, 3D-conformal radiation therapy. J Neurooncol 48:151-160.

[30] Milosevic MF, Frost PJ, Laperriere NJ, Wong CS, Simpson WJ (1996) Radiotherapy for atypical or malignant intracranial meningioma. Int J Radiat Oncol Biol Phys 34:817-822.

[31] Rockhill J, Mrugala M, Chamberlain MC (2007) Intracranial meningiomas: an overview of diagnosis and treatment. Neurosurg Focus 23:E1.

[32] Skeie BS, Enger PO, Skeie GO, Thorsen F, Pedersen PH (2010) Gamma knife surgery of meningiomas involving the cavernous sinus: long-term follow-up of 100 patients. Neurosurgery 66:661668; discussion 668-679.

[33] Fishbein WN, Carbone PP (1963) Hydroxyurea: Mechanism of action. Science 142:1069-1070.

[34] Newton HB (2007) Hydroxyurea chemotherapy in the treatment of meningiomas.Neurosurg Focus. 23(4):E11.

[35] Weston GJ, Martin AJ, Mufti GJ, Strong AJ, Gleeson MJ (2006) Hydroxyurea treatment of meningiomas: a pilot study. Skull Base 16:157-160.

[36] Schrell UM, Rittig MG, Anders M, Koch UH, Marschalek R, et al. (1997) Hydroxyurea for treatment of unresectable and recurrent meningiomas. II. Decrease in the size of meningiomas in patients treated with hydroxyurea. J Neurosurg 86:840-844.

[37] Rosenthal MA, Ashley DL, Cher L (2002) Treatment of high risk or recurrent meningiomas with hydroxyurea. J Clin Neurosci 9:156158.

[38] Koukourakis MI, Koukouraki S, Fezoulidis I, Kelekis N, Kyrias G, et al. (2000) High intratumoural accumulation of stealth liposomal doxorubicin (Caelyx) in glioblastomas and in metastatic brain tumours. Br J Cancer 83:1281-1286.

[39] Fabel K, Dietrich J, Hau P, Wismeth C, Winner B, et al. (2001) Longterm stabilization in patients with malignant glioma after treatment with liposomal doxorubicin. Cancer 92:1936-1942.

[40] Kvols LK, Woltering EA (2006) Role of somatostatin analogs in the clinical management of non-neuroendocrine solid tumors. Anticancer Drugs 17:601-608.

[41] Kunert-Radek J, Stepien H, Radek A, Pawlikowski M (1987) Somatostatin suppression of meningioma cell proliferation in vitro. Acta Neurol Scand 75:434-436.

[42] Chamberlain MC, Glantz MJ, Fadul CE (2007) Recurrent meningioma: salvage therapy with long-acting somatostatin analogue. Neurology 69:969-973.

[43] Schulz C, Mathieu R, Kunz U, Mauer UM (2011) Treatment of unresectable skull base meningiomas with somatostatin analogs. Neurosurg Focus 30:E11.

[44] Hammond S, Norden A, Drappatz J, et al. (2011) Phase II study of monthly Pasireotide (SOM230C) for recurrent or progressive meningioma. J Clin Oncol 29:150s; abstract 2040. 
[45] Ferrara N, Gerber HP, LeCouter J (2003) The biology of VEGF and its receptors. Nat Med 9:669-676.

[46] Schmid S, Aboul-Enein F, Pfisterer W, Birkner T, Stadek C, et al. (2010) Vascular endothelial growth factor: the major factor for tumor neovascularization and edema formation in meningioma patients. Neurosurgery 67:1703-1708.

[47] Provias J, Claffey K, delAguila L, Lau N, Feldkamp M, et al. (1997) Meningiomas: role of vascular endothelial growth factor/vascular permeability factor in angiogenesis and peritumoral edema. Neurosurgery 40:1016-1026.

[48] Duda DG, Jain RK, Willett CG (2007) Antiangiogenics: the potential role of integrating this novel treatment modality with chemoradiation for solid cancers. J Clin Oncol 25:4033-4042.

[49] Simon M, Boström JP, Hartmann C (2007) Molecular genetics of meningiomas: from basic research to potential clinical applications. Neurosurgery 60:787-798.

[50] Johnson M, Toms S (2005) Mitogenic signal transduction pathways in meningiomas: novel targets for meningioma chemotherapy? J Neuropathol Exp Neurol 64:1029-1036.

[51] Wang JL, Nistér M, Hermansson M, Westermark B, Pontén J (1990) Expression of PDGF beta-receptors in human meningioma cells. Int J Cancer 46:772-778.

[52] Maxwell M, Galanopoulos T, Hedley-Whyte ET, Black PM, Antoniades HN (1990) Human meningiomas co-express platelet-derived growth factor (PDGF) and PDGF-receptor genes and their protein products. Int J Cancer 46:16-21.

[53] Johnson MD, Woodard A, Kim P, Frexes-Steed M (2001) Evidence for mitogen-associated protein kinase activation and transduction of mitogenic signals by platelet-derived growth factor in human meningioma cells. J Neurosurg 94:293-300.

[54] Black PM, Carroll R, Glowacka D, Riley K, Dashner K (1994) Plateletderived growth factor expression and stimulation in human meningiomas. J Neurosurg 81:388-393.

[55] Wen PY, Yung WK, Lamborn KR, Norden AD, Cloughesy TF, et al. (2009) Phase II study of imatinib mesylate for recurrent meningiomas (North American Brain Tumor Consortium study 01-08). Neuro Oncol 11:853-860.

[56] Reardon DA, Norden AD, Desjardins A, Vredenburgh JJ, Herndon JE, et al. (2012) Phase II study of Gleevec(R)plus hydroxyurea (HU) in adults with progressive or recurrent meningioma. J Neurooncol 106:409-415.

[57] Horak P, Wöhrer A, Hassler M, Hainfellner J, Preusser M, et al. (2012) Imatinib mesylate treatment of recurrent meningiomas in preselected patients: a retrospective analysis. J Neurooncol 109:323-330. 